\title{
Simultaneous Determination of Theophylline and Caffeine Using Poly(L-phenylalanine)-Reduced Graphene Oxide Modified Glassy Carbon Electrode
}

\author{
Lin Zhang ${ }^{l}$, Ting Wang ${ }^{2}$, Xinxia Fan $^{l}$, Dongmei Deng ${ }^{1, *}$, Yuanyuan Li $^{1}$, Xiaoxia Yan ${ }^{l}$, \\ Liqiang Luo ${ }^{1, *}$ \\ ${ }^{1}$ College of Sciences, Shanghai University, Shanghai 200444, PR China \\ ${ }^{2}$ School of Health \& Social Care, Shanghai Urban Construction Vocational College, Shanghai 201401, \\ PR China \\ *E-mail: luck@shu.edu.cn (L. Luo); dmdeng@shu.edu.cn (D. Deng)
}

doi: $10.20964 / 2021.04 .22$

Received: 8 December 2020 / Accepted: 22 January 2021 / Published: 28 February 2021

\begin{abstract}
Theophylline (TP) and caffeine (CF) are two purine alkaloids which widely exist in our human diet. In the present work, poly(L-phenylalanine)-reduced graphene oxide $(\mathrm{P}(\mathrm{L}-\mathrm{Pal}) / \mathrm{rGO})$ modified glassy carbon electrode (GCE) was fabricated and applied to simultaneously determine the concentrations of $\mathrm{TP}$ and $\mathrm{CF}$. The $\mathrm{P}(\mathrm{L}-\mathrm{Pal}) / \mathrm{rGO}$ composite film was prepared by one-step electropolymerization using cyclic voltammetry, and the surface morphology was investigated by scanning electron microscope. The electrochemical behaviors of $\mathrm{TP}$ and $\mathrm{CF}$ on $\mathrm{P}(\mathrm{L}-\mathrm{Pal}) / \mathrm{rGO} / \mathrm{GCE}$ were investigated using cyclic voltammetry and differential pulse voltammetry. By optimizing parameters, the fabricated sensor exhibited excellent performance to simultaneously determine TP and CF in a wide linear range of 1-260 $\mu \mathrm{M}$. The detection limits were 0.35 and $0.5 \mu \mathrm{M}(\mathrm{S} / \mathrm{N}=3)$, respectively. The presented method shows good sensitivity and stability, and can be used for the determination of TP and CF in samples of green tea, coffee and tablets.
\end{abstract}

Keywords: Poly(L-phenylalanine); Reduced graphene oxide; Electropolymerization; Simultaneous determination.

\section{$\underline{\text { FULL TEXT }}$}

(C) 2021 The Authors. Published by ESG (www.electrochemsci.org). This article is an open access article distributed under the terms and conditions of the Creative Commons Attribution license (http://creativecommons.org/licenses/by/4.0/). 